\title{
Numerical Modelling of Non-metallic Inclusion Separation in a Continuous Casting Tundish
}

\author{
Marek Warzecha \\ Czestochowa University of Technology \\ Poland
}

\section{Introduction}

Nowadays the cleanliness of steel plays a major role for steel producers. It is defined by the size and number of non-metallic inclusions in the final product. Today, the dominating method of global steel production is continuous casting. A continuous casting plant includes the ladle turret, several steel ladles, a tundish, and mould/moulds. Tundish buffers steel melt during the ladle change and distributes the steel melt to several strands. Tundish plays also an important role in removing non-metallic inclusions (i.e. $\mathrm{Al}_{2} \mathrm{O}_{3}$ or $\mathrm{SiO}_{2}$ ), to the slag layer due to buoyancy force. The aluminium oxides are very hard and destroy steel structure during plastic formation process. Therefore strict steel quality conditions require a steady increase in the purity of steels and thus reducing the number and size of non-metallic inclusions is necessary.

Measurements of the melt flow and inclusions transport and separation in a steel mill, at working conditions, are nearly impossible due to the high temperatures and opacity of the fluid. The solution is using the physical and numerical simulations in this field of investigation. Water can be used for the physical simulation because the kinematic viscosities of liquid steel and water are comparable $\left(v_{\mathrm{st}, 1536^{\circ} \mathrm{C}}=8.26 \cdot 10^{-7} \mathrm{~m}^{2} / \mathrm{s}, v_{\mathrm{w}, 20^{\circ} \mathrm{C}}=\right.$ $10.0 \cdot 10^{-7} \mathrm{~m}^{2} / \mathrm{s}$ ), thus the flows of both fluids are similar. A wide review of such investigation was first done by Mazumdar and Guthrie (Mazumdar \& Guthrie, 1999) and lately by Chattopadhyay et al. (Chattopadhyay et al., 2010). From this reviews it can be seen, that experimental measurements using water models are widely used, and considering the similarity laws, the results from water modelling can be transferred to the real process. Though, many publications are available with water model experiments, only a few experimental studies were done on particle separation in the tundish.

Tundish flow and accompanying inclusion separation process are strongly investigated with Computational Fluid Dynamics (CFD) models as well. Numerous studies can be found in literature. Present state of the CFD techniques allow to calculate the fluid flow in tundish with the satisfying accuracy. This is confirmed by a good agreement in flow fields predicted mathematically and measured by laser-optical method using water models (Braun et al., 2010). For turbulence modelling, the standard or realizable $\mathrm{k}-\varepsilon$ models are mostly used, rather than Reynolds Stress Model (RSM) or Large-Eddy Simulations (LES). Results show that in many engineering problems, flow field is well described by steady-state numerical simulations using the Reynolds-Averaged Navier-Stokes (RANS) equations combined with the realizable $\mathrm{k}-\varepsilon$ model. 
On pre-calculated flow and turbulence field, the transport of disperse phase can be treated.

The weakness of mathematical model lies in defining boundary conditions for a disperse phase (inclusions). A lot of publications can be found where researchers investigate particle separation. However lots of assumptions have been made so far. Usually at boundaries like the fluid-fluid (liquid steel-slag interface, free surface) and fluid-solid (liquid steel-tundish lining) standard boundary conditions are used. It is assumed that if inclusion reaches one of these boundaries, it is either reflected or absorbed. In this way, the deposition of particles at these boundaries are not fully reproduced. A more detailed physical examination of inclusion separation is needed. Solutions, where a special model is applied for the melt surface or tundish walls belong to minorities (Zhang et al., 2000).

The aim of numerical studies should be focused on finding and implementing a proper boundary condition for modelling the particle separation at the covering slag and lining interface. Only after successful validation with experimental results, the mathematical model can be used to simulate the non-metallic inclusions movement in the liquid steel bath and separation at the steel-slag interface for industrial process conditions.

\section{Tundish description}

Investigated object is a six-strand continuous casting tundish operating in one of a Polish steel mill. The nominal capacity of the tundish is $15 \mathrm{Mg}$ of liquid steel. The tundish is used for casting ingots intended for production of small cross-section rolled products. It is symmetrical with respect to its central cross-section. In its current configuration the tundish is furnished with an impact pad. The basic refractory lining is made up of andalusite tiles, and the working layer - a high-magnesite gunite mix. It is used for casting sequences composed of from several to more than ten heats. Figure 1 shows the geometry of the tundish with its major dimensions. The dimensions of the tundish are given in Table 1.
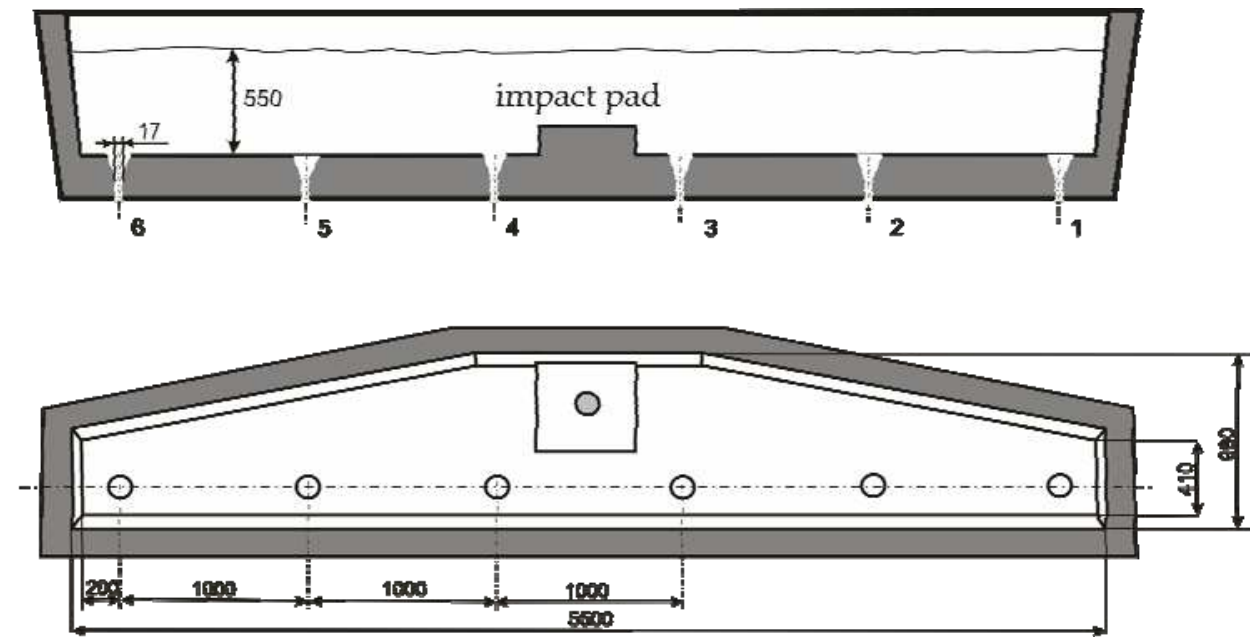

Fig. 1. Geometry of the investigated tundish 


\begin{tabular}{|c|c|}
\hline Nominal capacity $(\mathrm{Mg})$ & 15 \\
Tundish length (bottom) $(\mathrm{m})$ & 5.4 \\
Tundish width (bottom) $(\mathrm{m})$ & 0.82 \\
Inclination of the side walls $\left(^{\circ}\right)$ & 7 \\
Steel filling level $(\mathrm{m})$ & 0.55 \\
Number of nozzles $(-)$ & 6 \\
Nozzle diameter $(\mathrm{m})$ & 0.017 \\
\hline
\end{tabular}

Table 1. Dimensions of the investigated tundish

Large differences in steel quality specified by the number of non-metallic inclusions, between individual strands for the former industrial six-strand tundish configuration have been the basis for undertaking the presented studies. The aim of the performed investigations ware to improve the billets quality and to decrease observed differences in inclusion density in billets casted at individual strands. To improve the inclusion separation rate in the studied tundish, flow conditions have to be changed. It can be reached by installing a flow control device (FCD) in the tundish working space. FCD proposed here is a pair of dams (see Figure 2). For steelwork such device is cheap and easy solution from technical point of view.

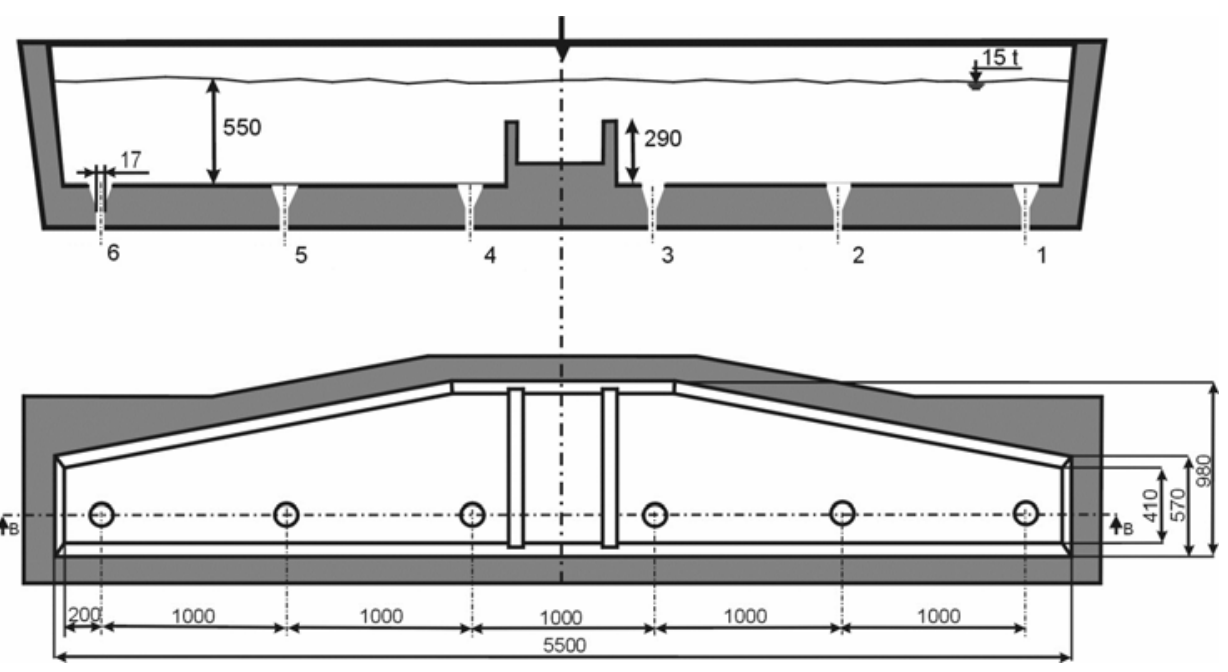

Fig. 2. Tundish configuration studied in presented work

\section{Industrial investigation of inclusions distribution in the steel}

Tests were carried out with industrial conditions at a continuous casting tundish working at one of a Polish steel mill. The investigation was performed to identify the distribution of non-metallic inclusions in steel ingot by analysing samples taken from billet casted in the investigated tundish. The study included quantitative and partly qualitative analysis of nonmetallic inclusions found in square ingots $\left(160 \times 160 \mathrm{~mm}^{2}\right)$ of BSt500S steel grade. The 
analysis included samples cut from three billets (numbered: 1, 2 and 3), at the beginning and the end of casted ladle. The system of numbering of cc machine moulds in steelwork is shown in Figure 1. The samples were cut from the cross-section of the billets in the manner demonstrated in Figure 3. The surface of the samples was analysed using computerized image analysis system. For statistical reasons 10 fields (one field area of $8.77 \cdot 10^{5} \mu \mathrm{m}^{2}$ ) on one sample were tested with a 200x magnification.

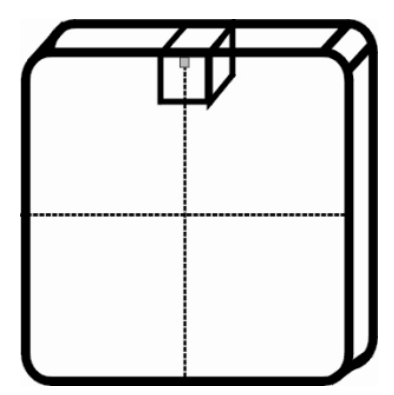

Fig. 3. Sampling method in billets

\section{Numerical model - equations, parameters and boundary conditions}

The CFD numerical simulations where carried out on the basis of the RANS equations. The liquid phase Navier-Stokes equations for incompressible flow without source terms are as follows.

Continuity equation:

$$
\frac{\partial u_{i}}{\partial x_{i}}=0
$$

Momentum conservation equation:

$$
\rho \frac{\partial u_{i}}{\partial t}+\rho u_{j} \frac{\partial u_{i}}{\partial x_{j}}=-\frac{\partial p}{\partial x_{i}}+\frac{\partial}{\partial x_{j}}\left[\mu_{\text {eff }}\left(\frac{\partial u_{i}}{\partial x_{j}}+\frac{\partial u_{j}}{\partial x_{i}}\right)\right]+\rho g_{i}
$$

where

$$
\mu_{\mathrm{eff}}=\mu+\mu_{\mathrm{t}}
$$

and where and: $u_{i, j}$ is time-averaged fluid velocities in the $i$ th and $j$ th directions respectively, $\rho$ is liquid density, $p$ is pressure in the fluid, $\mu$ is molecular viscosity of liquid, $\mu_{t}$ is turbulent viscosity, $\mu_{\text {eff }}$ is effective turbulent viscosity, $g_{i}$ is gravitational acceleration in the $i$ th direction, $x_{i}, x_{j}$ are spatial coordinates in the $i$ th and $j$ th directions, $i, j$ denote the three directions in the global Cartesian coordinate system.

Regarding heat transfer, the turbulent energy equation can be written as:

$$
\frac{\partial}{\partial t}(\rho h)+\frac{\partial}{\partial x_{i}}\left(\rho h u_{i}\right)=\frac{\partial}{\partial x_{j}}\left[\left(k+\frac{c_{p} \mu_{t}}{\sigma_{t}}\right) \frac{\partial T}{\partial x_{j}}\right]
$$


where $h$ is enthalpy, $k$ is thermal conductivity, $c_{p}$ is heat capacity of liquid water, $\sigma_{t}$ is turbulent Prandtl number, $T$ is temperature.

Turbulent flows occur during liquid steel flow through the tundish. When modelling the process a turbulence model has to be chosen. In practice, diffusion turbulence models of a simplified structure are used, which have been verified in many engineering applications with good results. For most tundish flows numerical calculations, the standard k- $\varepsilon$ model is used. However some investigations (Solorio-Diaz et al., 2004; Hou \& Zou, 2005) demonstrate that this model does not give sufficient results for all cases. Investigations with water model (Braun et al., 2010) has shown that the overall flow phenomena in the tundish is well described by steady-state numerical simulations using RANS equations combined with the realizable $k-\varepsilon$ model from Shih et al. (Shih et al., 1995). This model is a good compromise between accuracy and simulation time. The realizable $k-\varepsilon$ model is based on the Boussinesq approximation, saying that the Reynolds stresses are a function of the mean gradients of velocity similar to the molecular stress. The unknown value is the turbulent viscosity:

$$
\mu_{\mathrm{T}}=\rho \mathrm{C}_{\mu} \frac{\mathrm{k}^{2}}{\varepsilon}
$$

which is a function of the turbulent kinetic energy $k$ and the dissipation rate of the turbulent kinetic energy $\mathcal{\varepsilon}$.

In the realizable $\mathrm{k}-\varepsilon$ model $C_{\mu}$ is a function of the gradients of velocity, whereby mathematical restrictions of the standard k- $\varepsilon$ model are avoided. A further modification represents a new differential equation for the dissipation rate $\varepsilon$.

Equation of the turbulent kinetic energy k:

$$
\frac{\partial}{\partial t}(\rho \mathrm{k})+\frac{\partial}{\partial \mathrm{x}_{\mathrm{i}}}\left(\rho \mathrm{ku} \mathrm{u}_{\mathrm{i}}\right)=\frac{\partial}{\partial \mathrm{x}_{\mathrm{j}}}\left[\left(\mu+\frac{\mu_{\mathrm{t}}}{\sigma_{\mathrm{k}}}\right) \frac{\partial \mathrm{k}}{\partial \mathrm{x}_{\mathrm{j}}}\right]+\mathrm{G}_{\mathrm{k}}+\mathrm{G}_{\mathrm{b}}-\rho \varepsilon
$$

Equation of the dissipation rate of the turbulent kinetic energy $\varepsilon$ :

$$
\frac{\partial}{\partial t}(\rho \varepsilon)+\frac{\partial}{\partial x_{j}}\left(\rho \varepsilon u_{j}\right)=\frac{\partial}{\partial x_{j}}\left[\left(\mu+\frac{\mu_{t}}{\sigma_{\varepsilon}}\right) \frac{\partial \varepsilon}{\partial x_{j}}\right]+\rho C_{1} S \varepsilon-\rho C_{2} \frac{\varepsilon^{2}}{k+\sqrt{v \varepsilon}}+C_{1 \varepsilon} \frac{\varepsilon}{k} C_{3 \varepsilon} G_{b}
$$

where $G_{k}$ is generation of turbulence kinetic energy due to the mean velocity gradients, $G_{b}$ is generation of turbulence kinetic energy due to buoyancy, $C_{1}, C_{2}$ and $C_{1 \varepsilon}, C_{3 \varepsilon}$ are constants, $\sigma_{k}$ and $\sigma_{\varepsilon}$ are turbulent Prandtl numbers for $k$ and $\varepsilon$ respectively.

The model constants are $\mathrm{C}_{1 \varepsilon}=1.44, \mathrm{C}_{2}=1.9, \sigma_{k}=1.0, \sigma_{\varepsilon}=1.2$.

The flow field in tundish is calculated using commercial CFD software Fluent. The partial differential equations are solved with the help of mentioned below boundary conditions for all control volumes. To provide higher order accuracy a second order upwind scheme is used. SIMPLEC algorithm is used to resolve the pressure-velocity coupling in the momentum equation.

Because of symmetry plane only a half of the tundish is simulated. One half of a tundish working space is reproduced by a hybrid computational grid with about 0.4 to 0.5 million of control volumes, depending on tundish configuration. 


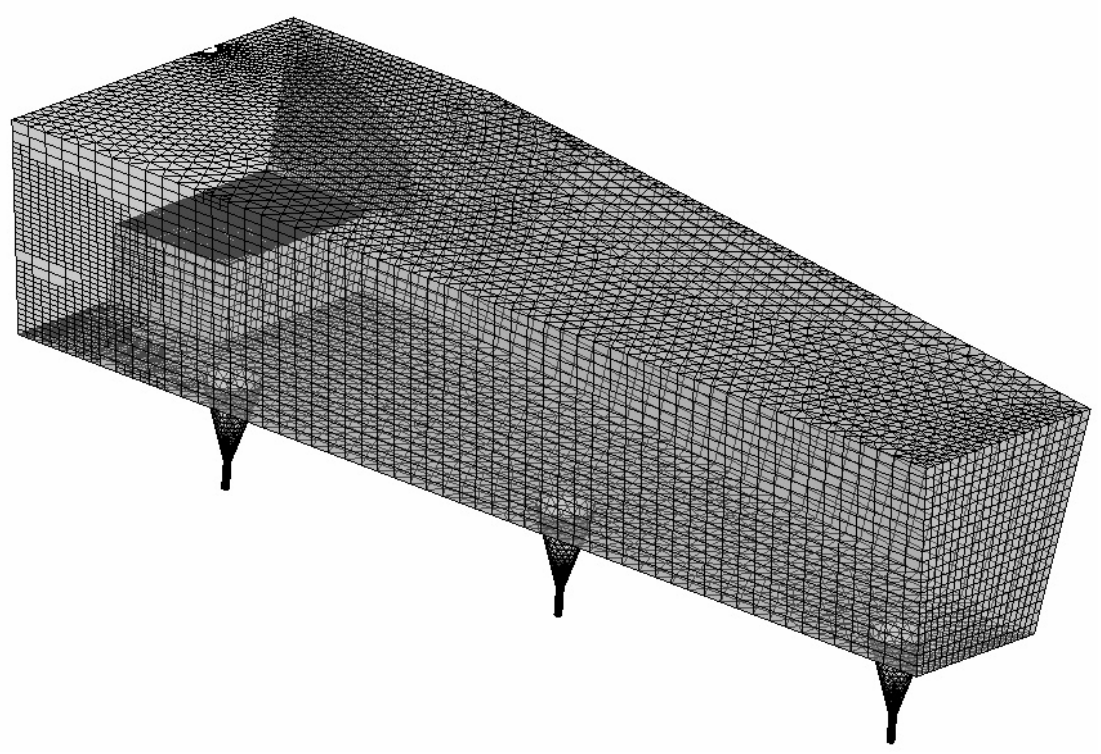

Fig. 4. Hybrid computational grid of the tundish working space

For inlet and nozzle outlet ports smaller grid spacing is used by applying mesh refinement. A symmetry boundary condition is given at a symmetry plane, which implies a zero gradient condition for all variables normal to the plane. Steel-slag interface is assumed to be flat and modeled as a frictionless wall. Deformations of the liquid steel surface can be neglected since its effect on the flow structure in the tundish is small. Side walls and bottom of the tundish as well as additional tundish equipment have stationary wall boundary condition for the velocity components and the turbulence quantities, so called "standard wall function". The inlet velocity of liquid steel is equal to $2.2 \mathrm{~m} / \mathrm{s}$, which is equivalent to billet casting speed in the order of $1.7 \mathrm{~m} / \mathrm{min}$. The velocity profile in the shroud is assumed to be flat with a turbulent intensity of $5 \%$. The inlet temperature of the liquid steel stream is $1823 \mathrm{~K}$. Heat losses along the slag cover and side walls/bottom of the tundish are taken from references (Joo \& Guthrie, 1991; Chakraborty \& Sahai, 1992) and are given in Table 2. At the outlets of the tundish a fixed pressure is applied.

On pre-calculated flow and turbulence field, the transport of disperse phase can be treated. There are two ways of modelling the discrete phase transport. First is the simple diffusion/convection approach. The particle concentration (defined as the number of particles per unit volume) and movement, due to turbulent transport and diffusion, is modelled by solving a transport equation, with the particle rise velocity as an extra convective component in the upward direction. The terminal rising velocity of particle is added when particle concentration is the dependent variable. The second approach is a full trajectory calculation. In this approach, each particle is treated separately and its trajectory is calculated by integrating local velocity. The differential equation, describing the motion of particles in the liquid, considers the different forces acting on particle, such as drag force, buoyancy force, added mass force and additional forces. 


\begin{tabular}{|r|l|}
\hline Liquid steel density $\left(\mathrm{kg} / \mathrm{m}^{3}\right)$ & 7010 \\
Liquid steel dynamic viscosity $(\mathrm{kg} / \mathrm{m} \cdot \mathrm{s})$ & 0.007 \\
Inlet velocity $(\mathrm{m} / \mathrm{s})$ & 2.2 \\
Inlet temperature $(\mathrm{K})$ & 1823 \\
Specific heat $(\mathrm{J} / \mathrm{kg} \cdot \mathrm{K})$ & 821 \\
Thermal conductivity $(\mathrm{W} / \mathrm{m} \cdot \mathrm{K})$ & 30.5 \\
Heat flux through side walls $/$ bottom $\left(\mathrm{kW} / \mathrm{m}^{2}\right)$ & -2.6 \\
Heat flux through slag cover $\left(\mathrm{kW} / \mathrm{m}^{2}\right)$ & -16 \\
Inclusion density $/ \mathrm{Al}_{2} \mathrm{O}_{3} /\left(\mathrm{kg} / \mathrm{m}^{3}\right)$ & 3960 \\
\hline
\end{tabular}

Table 2. Technological operating conditions of the tundish used in simulations

In presented studies full trajectory approach is applied. The inclusion movement is simulated in Fluent using the Discrete Phase Model (DPM). The differential equation describing the motion of inclusions in the liquid steel is:

$$
\frac{\mathrm{d} \mathrm{u}_{\text {inc. }}}{\mathrm{dt}}=\frac{3 \mu_{\text {st. }} C_{\mathrm{D}} \operatorname{Re}_{\mathrm{p}}}{4 \rho_{\text {inc. }} \mathrm{d}_{\text {inc. }}^{2}}\left(\mathrm{u}_{\text {st. }}-\mathrm{u}_{\text {inc. }}\right)+\frac{\mathrm{g}\left(\rho_{\text {inc. }}-\rho_{\text {st. }}\right)}{\rho_{\text {inc. }}}+\frac{1}{2} \frac{\rho_{\text {st. }}}{\rho_{\text {inc. }}} \frac{\mathrm{d}}{\mathrm{dt}}\left(\mathrm{u}_{\text {st. }}-\mathrm{u}_{\text {inc. }}\right)+\frac{\rho_{\text {st. }}}{\rho_{\text {inc. }}} \frac{\mathrm{d} \mathrm{u}_{\text {st. }}}{\mathrm{dt}}
$$

where $u_{\text {inc., }} u_{\text {st. }}$ are inclusion or liquid steel velocity, $\rho_{\text {inc., }} \rho_{\text {st. }}$ are inclusion or liquid steel density, $d_{i n c}$ is inclusion diameter, $C_{D}$ is drag coefficient, $R e_{p}$ is particle Reynolds number, $g$ is gravitational constant, $\mu_{\text {st. }}$ is molecular viscosity of the liquid steel.

The first term on the right hand side of equation (8) describes the drag force, the second term the buoyancy force, the third one the "virtual mass" force and the last one an additional force arising due to the pressure gradient in the fluid.

Inclusions travel through steady-state flow field. In industrial process non-metallic inclusions come to the tundish as deoxidization products together with steel from the ladle or are the product of tundish lining erosion or slag re-entering the melt. In this work only inclusions that originate as deoxidization products are considered. In the numerical simulations thus inclusions come to the tundish with liquid steel, with the same initial velocities as steel. Inclusions are spherical and their density ratio to liquid steel equals 0.56 . Presented investigations concentrate on inclusion separation due to flotation. The results do not include other mechanisms of inclusion removal. Therefore inclusions are reflected from all solid surfaces and can come out only through one of the outlets or can be separated at the steel-slag interface (see Figure 5). Coalescence of inclusions is not considered here.

The transport equation is solved for each particle as it travels through the previously calculated flow field. A discrete random walk (DRW) model is applied to model the chaotic effect of the fluid turbulence on inclusion trajectories. In this model a fluctuant-random velocity vector is added to the calculated time average vector, in order to obtain the inclusion velocity at each time-step as it travels through the melt.

Based on the experimental results of the inclusions distribution in testing samples of steel, the numerical simulations have been performed for selected sizes: 2, 5, 10, 20, 30, 40 and 50 $\mu \mathrm{m} .1000$ inclusions are released from the inlet surface and their trajectories are calculated with discrete random walk model. Injection of particles with one group size is repeated five times and the total separation rate is an average value form five probes. 


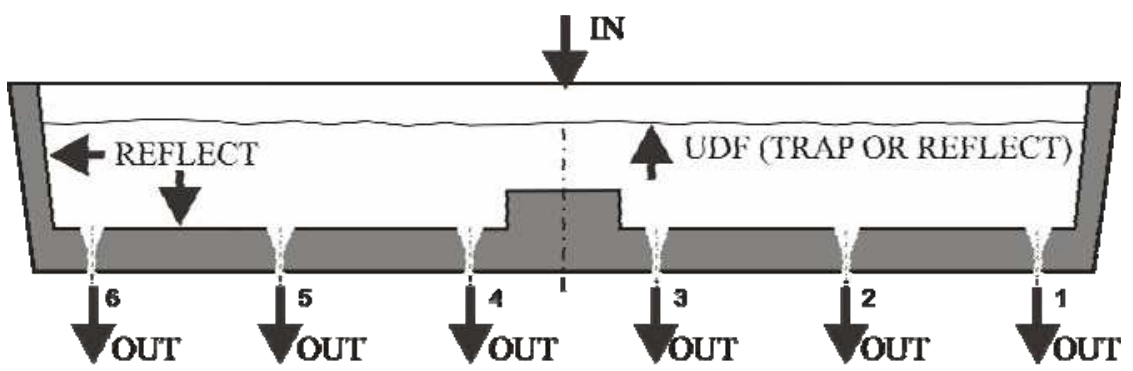

Fig. 5. Boundary conditions for the DPM model in numerical simulations

The separation rate is calculated from the number of inclusions injected to the tundish through the shroud $\left(\mathrm{N}_{\text {in }}\right)$ and the number of inclusions counted at the outlets of the tundish ( $\mathrm{N}_{\text {out }}$.

$$
\beta=\left(\mathrm{N}_{\text {in }}-\mathrm{N}_{\text {out }}\right) / \mathrm{N}_{\text {in }}
$$

where: $\beta$ is inclusion separation rate, $N_{i n}$ is number of inclusions which come into the tundish through the shroud, $N_{\text {out }}$ is number of inclusions which come out through the outlets.

It this way inclusion separation due to flotation is considered. The other mechanisms are not considered in this work but flotation is the dominating mechanism of inclusions removal in tundishes.

\section{Results and discussion}

The results are presented in two sections. The first section focuses on the industrial estimations of inclusions composition and size distribution. The second section concentrates on numerical modelling. This section describe first the flow structure and its changes due to the tundish working space modification. In the second part inclusion separation from liquid steel and their distribution to the individual strands are analysed.

\subsection{Industrial investigation}

Based on the industrial measurements the chemical composition and quantity of inclusions in the analysed area were estimated. Non-metallic inclusions in samples taken from the billets were identified mainly as oxides and sulphides. Detailed statistical characteristics have been defined and on their basis the distribution of non-metallic inclusions have been determined depending on their diameter. The results are given in Table 3.

Based on the presented size distributions of non-metallic inclusions found in samples it can be concluded that the dominating share have the inclusions, which do not exceed the diameter of $15 \mu \mathrm{m}$. It is only a little number of inclusions with diameter exceeding $50 \mu \mathrm{m}$. Similar results have been obtained by other plant investigations (Beskow et al., 2002; Zhang et al., 2003; EC Technical Report, 2005). This measurements performed also on aluminum killed steels have shown that the vast majority (about 90\%) of the inclusions in tundishes and continuously casted ingots constitute spherical inclusions of small size. In case of oxide inclusions, the largest share (average $70-80 \%$ ) is aluminum oxides. 


\begin{tabular}{|c|c|c|c|c|}
\hline \multirow{2}{*}{$\begin{array}{c}\text { Inclusion } \\
\text { diameters } \\
(\mu \mathrm{m})\end{array}$} & \multicolumn{3}{|c|}{$\begin{array}{c}\text { Share of identified inclusions in size group } \\
(\%)\end{array}$} \\
\cline { 2 - 5 } & \multicolumn{2}{|c|}{$\begin{array}{c}\text { billet casted at } \\
\text { nozzle } 1\end{array}$} & \multicolumn{2}{|c|}{$\begin{array}{c}\text { billet casted at } \\
\text { nozzle 2 }\end{array}$} \\
\cline { 2 - 5 } & Cast 1 & Cast 2 & Cast 1 & Cast 2 \\
\hline $0 \div 5$ & 60.5 & 63.2 & 53.1 & 49.2 \\
\hline $5 \div 15$ & 24.8 & 20.4 & 24.9 & 27.9 \\
\hline $15 \div 25$ & 3.4 & 8.1 & 10.7 & 12.8 \\
\hline $25 \div 35$ & 4.7 & 4.2 & 3.6 & 3.1 \\
\hline $35 \div 45$ & 2.0 & 0.1 & 2.2 & 1.2 \\
\hline $45 \div 60$ & 0.9 & 1.6 & 3.6 & 2.8 \\
\hline
\end{tabular}

Table 3. Non-metallic inclusions identified in the continuous casted billets during industrial experiment

\subsection{Numerical investigations}

Numerical simulations are used to calculate the liquid flow structure in the tundish and to predict the inclusion separation rates. First, the current tundish configuration has to be diagnosed. Than tundish equipped with dams is numerically investigated.

\subsubsection{Flow structure and its influence on inclusion separation due to flotation}

Analysis of the flow field and temperature distribution in the former tundish have been the topics of earlier studies published elsewhere (Jowsa et al., 2006; Merder et al., 2007; Jowsa et al., 2007). This research work revealed that the industrial tundish in its basic configuration is characterized by the unfavorable hydrodynamic casting conditions. Among other things, not much ascending streams can be found and they are essential for growing and separating inclusions due to their flotation.

Working space of the tundish has been equipped with dams. The main task of the dams is to reorient and direct the flow of the liquid steel stream. Installing dams in the inlet zone has created a space limited by them, which is a kind of container controlling the turbulence of the flow. Thanks to that the inlet zone is separated from the nozzle zone, which as a consequence should contribute to the reduction of the transient zone, increase of the share of dispersed plug flow and improve of the liquid steel inclusion refining conditions. Fluid flow topologies at the inlet region in the investigated tundish equipped with an impact pad (current configuration) and with dams (modified configuration) are shown in Figure 6.

Figure 7 shows that in the current tundish configuration a step between impact pad and bottom of the tundish direct liquid steel stream to the tundish bottom. It creates a short circuit between inlet and one of the outlet nozzles (number 3). A direct flow of the part of the liquid steel can be the reason of decreasing the quality of billet casted at this strand since small inclusions are transported with steel.

The situation is changing if incoming steel stream meets dams. In this case fluid is directed to the steel-slag interface helping to remove inclusions due to their flotation to the covering 
slag. It is expected that dams help to improve steel quality and decrease the differences between individual strands.
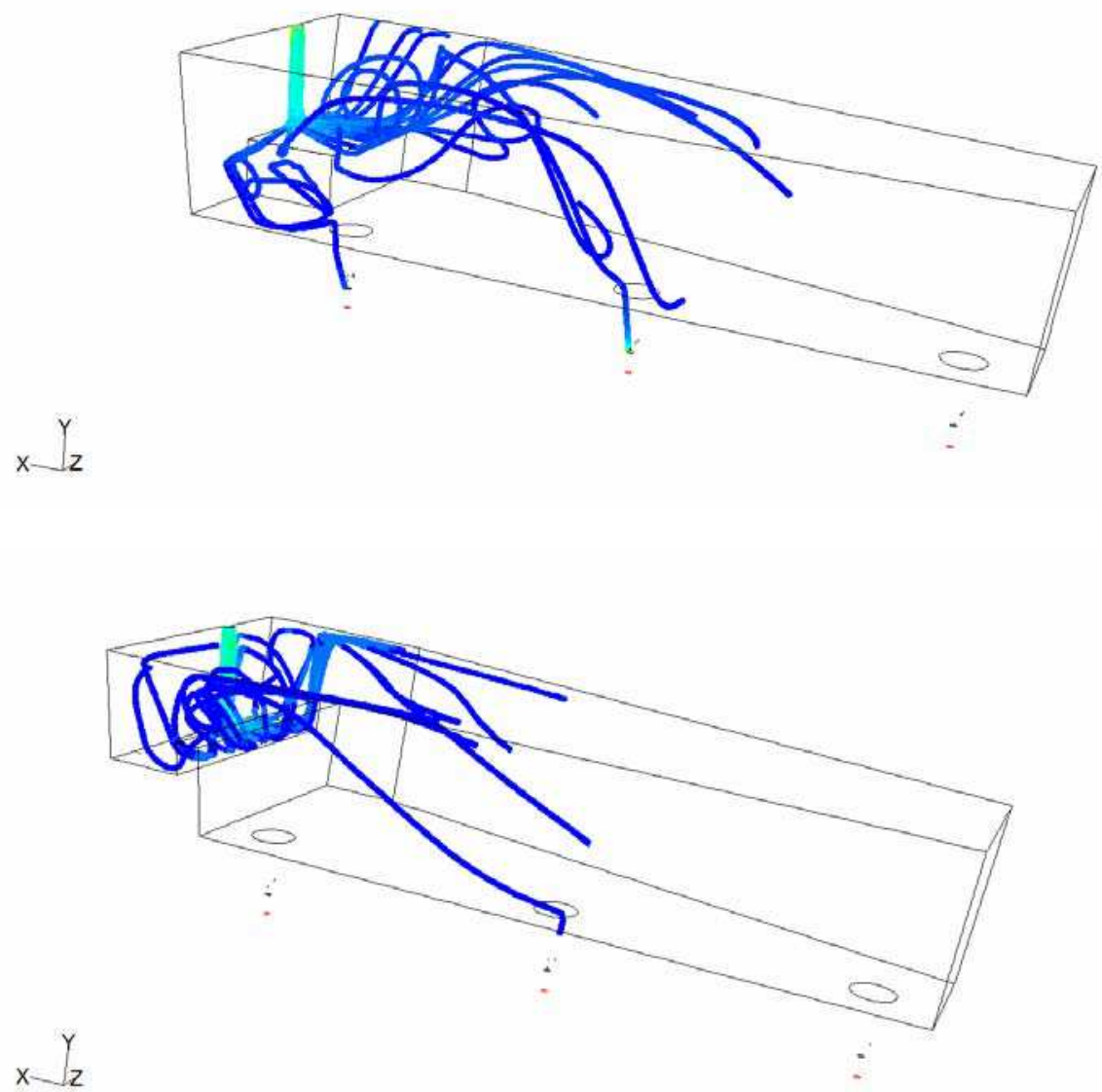

Fig. 6. A fluid flow topology at the inlet region in the investigated tundish equipped with an impact pad (top view, current configuration) and with dams (bottom view, modified configuration)

\subsubsection{CFD predictions of inclusions separation in the tundish}

Numerical simulations have been performed to calculate the inclusion separation rates in currently working tundish configuration. Predicted numerically separation rates are shown in Figure 7. In the first simulation a standard (trap) boundary condition is used for inclusion separation. Using trap condition, it is assumed that all inclusions which reach the covering slag surface are separated. 


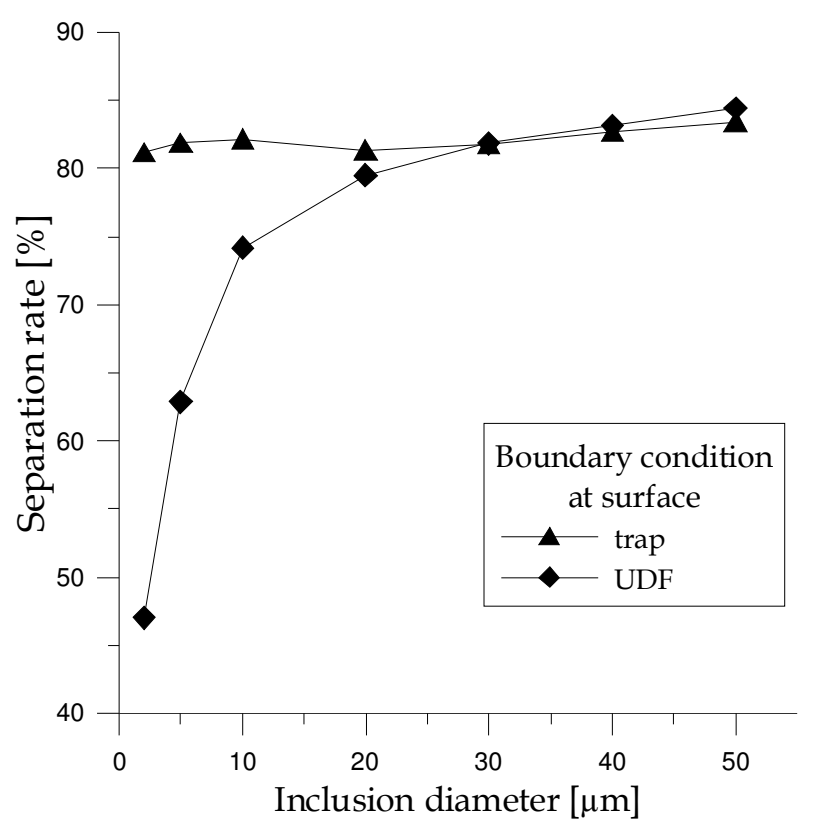

Fig. 7. Inclusions separation rate in the tundish with basic configuration

Figure 7 shows additionally the results obtained for the basic tundish configuration (with impact pad), calculated with modified boundary condition set at the steel-slag interface. It can be seen, that separation rate obtained with standard boundary condition is very high for all inclusion diameters. These results do not correspond to the values of inclusion numbers found in the billets. It is expected that the separation of the inclusions with considered diameters is much lover then predicted numerically.

Such a conclusion is confirmed additionally with results of particle separation performed using tundish water models (Martinez et al., 1986; Joo \& Guthrie, 1993; Rogler et al., 2005). This results indicate that separation rate of modeled micro inclusions (diameter less than 30 $\mu \mathrm{m})$, is very low, which means that they flow with the fluid and are nearly not separated at the water surface.

Rationales coming from industrial and laboratory investigations have been the reason for searching improved boundary condition describing the inclusion separation at the steel-slag interface. In its first approximation velocity of fluid in the vicinity of this border is considered. According to Engh (Engh et al., 1992) the critical velocity of fluid, above which the particle can be re-entrained to fluid, can be derived from a force balance. The shear force is calculated considering the drag force:

$$
\tau_{0} \pi r_{\text {inc. }}^{2}=\rho_{\text {st. }} u_{b}^{2} \varphi \pi r_{\text {inc. }}^{2}
$$

where $\tau_{0}$ is shear stress, $r_{i n c}$. is inclusion radius, $u_{b}$ is the velocity outside the boundary layer, $\varphi$ is an empirical friction factor, for a plane surface it is equal to:

$$
\varphi=0.03\left(\operatorname{Re}_{\mathrm{x}}\right)^{-1 / 5}
$$


with

$$
\operatorname{Re}_{\mathrm{x}}=\mathrm{u}_{\mathrm{b}} \mathrm{x} / \mathrm{v}_{\mathrm{st}}
$$

where $x$ is the distance from the leading edge of the plane and $v_{s t}$. is kinematic viscosity of liquid steel. With the approximation that the shear force and the gravity force are equal and opposite, the critical velocity can be described as:

$$
u_{b}=\left[\frac{4 g\left(\rho_{\text {st. }}-\rho_{\text {inc. }}\right) r_{\text {inc. }} x^{1 / 5}}{3 \rho_{\text {st. }} \cdot 0.03 v_{\text {st. }}^{1 / 5}}\right]^{5 / 9}
$$

The velocity $u_{b}$ has been included in the boundary condition at the surface via an UDF (User Defined Function). Velocity of the fluid in cell at the border where particle reach the surface is compared with the critical velocity. In case if the fluid velocity is lower than the critical velocity the particle is trapped, which means that the inclusion is absorbed by covering slag, otherwise particle come back to the computational domain which means that inclusion flows farther with the fluid.

More work need to be done to include additional forces. However the results obtained with the UDF function gave a better agreement with the experimental results and were a basis to use it also in simulations presented here. The numerical model with modified boundary condition has been previously validated with water model results obtained for the onestrand tundish model (Koitzsch et al., 2008).

This modified boundary condition is used to calculate the separation rates for tundish equipped with dams. The results showing the total separation rate values are shown in Figure 8 and the separation rate values for different strands are shown in Figures 9 and 10.

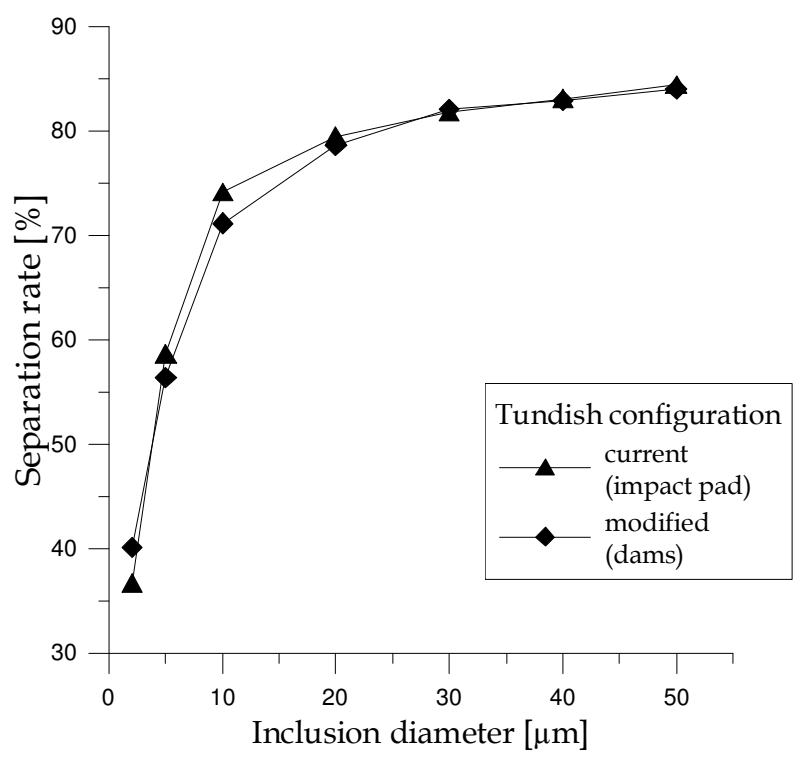

Fig. 8. Separation rate in current and modified tundish 
From the results presented in Figure 8 it can be seen that installation of dams in tundish working space does not change the separation rates for none of the investigated inclusion diameters. In Figures 9 and 10 inclusions which flow out from the tundish through the nozzles are counted. Percentage share for each nozzle is calculated. Results shown in Figure 9 concerns tundish with current configuration. It can be seen that number of inclusions flowing out through the nozzle no. 3 is much higher than through the other ones. This confirms the findings from fluid flow structure investigations. In Figure 6 one can see the short circuit that transport the inclusions directly to the outlet nozzle no. 3 . This can be the reason of differences in billet quality observed by the producer.

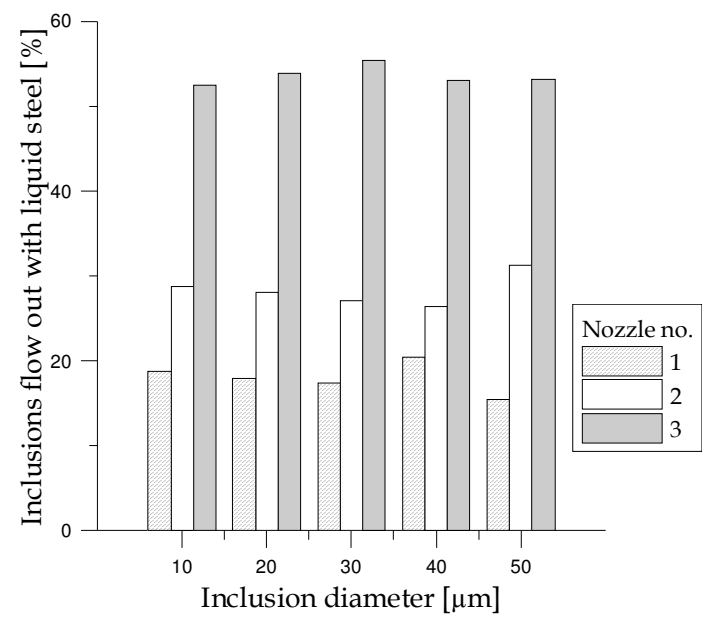

Fig. 9. Inclusions flowing with liquid steel through individual nozzles - tundish basic configuration

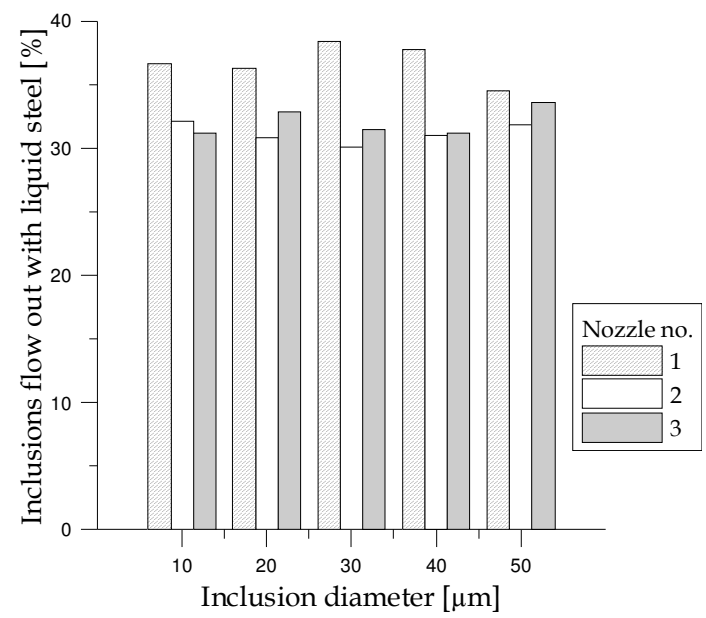

Fig. 10. Inclusions flowing with liquid steel through individual nozzles - tundish with dams 
Situation has changed after installing dams. The results showing inclusions flowing out to individual strands are shown in Figure 10. Appearance of dams did not improve the separation rate of inclusions in the investigated tundish (see Figure 8) but what is very important, thanks to them the quality of all billets casted with modified tundish should be very similar.

\section{Conclusion}

This chapter presented the application of Computational Fluid Dynamics (CFD) supported by experimental results to simulate liquid steel flow through the continuous casting tundish and non-metallic inclusions separation process.

The basis of performed studies were to show the differences in billets quality between individual strands observed for the former industrial six-strand tundish configuration. The aim of the studies was to diagnose the current tundish and to decrease the differences in quality of the strands.

The numerical simulations of liquid steel flow through the tundish were carried out using a commercial Computational Fluid Dynamics software Fluent. On pre-calculated flow field, the non-metallic inclusion separation in the investigated tundish is numerically investigated. To validate the numerical results, plant estimations and measurements done previously with water model were used.

The presented results concern the evaluation of the changes in non-metallic inclusion separation due to modifications of the tundish working space. The results of numerical simulation show that dams installed in tundish working space significantly decreased the differences in separation rates at the individual strands.

Future research is currently being carried out to improve boundary condition describing inclusion separation at the steel-slag interface and to estimate the inclusion distribution at the tundish outlets for validation of numerical model in prediction of separation rates.

\section{Acknowledgment}

The author would like to thank Prof J. Jowsa from the Czestochowa University of Technology for his advice and support and to Dr T. Merder from the Silesian University of Technology for cooperation in research work.

\section{References}

Beskow, K.; Jia, J.; Lupis, C.H.P.; Sicien, D. (2002). Chemical characteristics of inclusions formed at various stages during the ladle treatment of steel. Ironmaking $\mathcal{E}$ Steelmaking, Vol. 29, No. 6, (December 2002), pp. 427-435, ISSN 0301-9233

Braun, A.; Warzecha, M.; Pfeifer, H. (2010). Numerical and Physical Modeling of Steel Flow in a Two-Strand Tundish for Different Casting Conditions. Metal. and Mater. Trans. B, Vol. 41, No. 3, (June 2010), pp. 549-559, ISSN 1073-5615

Chakraborty, S.; Sahai, Y. (1992). Effect of holding time and surface cover in ladles on liquid steel flow in continuous casting tundishes. Metal. Trans. B, Vol. 23, No. 2, (Februar 1992), pp. 153-167, ISSN 1073-5615 
Chattopadhyay, K.; Isac, M.; Guthrie, R.I.L. (2010). Physical and mathematical modelling of steelmaking tundish operations: A review of the last decade (1999-2009). ISIJ International, Vol. 50, No. 3 (March 2010), pp. 331-348, ISSN 0915-1559

Engh, T.A.; Simensen, C.J.; Wijk, O. (1992). Principles of Metal Refining, Oxford University Press, ISBN 0-19-856337-X, USA

European Commission technical steel research report. (2005). Improved production control through rapid characterisation of non-metallic inclusions in steel, Final Report EUR 21627 EN, ISBN 92-894-9695-9

Hou, Q.; Zou, Z. (2005). Comparison between standard and renormalization group k- $\varepsilon$ models in numerical simulation of swirling flow tundish. ISIJ International, Vol. 45, No. 3, (March 2005), pp. 325-330, ISSN 0915-1559

Joo, S.; Guthrie, R.I.L. (1991). Heat flow and inclusion behaviour in a tundish for slab casting. Canadian Metall. Quarterly, Vol. 30, No. (1991), pp. 261-269, ISSN 1879-1395

Joo, S.; Guthrie, R.I.L. (1993). Inclusion behavior and heat-transfer phenomena in steelmaking tundish operations: part 1 aqueous modeling. Metal. and Mater. Trans. B, Vol. 24, No. 5, (October 1993), pp. 755-765, ISSN 1073-5615

Jowsa, J.; Boguslawski, A.; Garncarek, S.; Warzecha, M.; Merder, T.; Tyliszczak, A.; Cwudzinski, A. (2007). Research Report 3 T 08B 00626

Jowsa, J.; Derda, W.; Warzecha, M.; Merder, T.; Staniewski, I.; Cwudzinski, A. (2006). Numerical modelling of the mass, heat and momentum transfer during continuous casting of steel and in the ladle metallurgy processes. Metallurgy - Metallurgical Engineering news, No. 6, (June 2006), pp. 252-256, ISSN 1230-3534

Koitzsch, R.; Warzecha, M.; Ruckert, A.; Pfeifer, H. (2008). Physical and mathematical simulation of the inclusion removal and determination of the deposition rate for the continuous casting process. 6th European Conference on Continuous Casting (ECCC 2008), Riccione, Italy, 4 - 6 June 2008

Martinez, E.; Maeda, M.; Heaslip, L.J.; Rodriguez, G.; Mclean, A. (1986). Effects of fluid flow on the inclusion separation in continuous casting tundish. Transactions ISIJ, Vol. 26, No. 8, (August 1986), pp. 724-731, ISSN 0021-1583

Mazumdar, D.; Guthrie, R. I. L. (1999). The physical and mathematical modelling of continuous casting tundish systems. ISIJ International, Vol. 39, No. 6, (June 1999), pp. 524-547, ISSN 0915-1559

Merder, T.; Jowsa, J.; Warzecha, M.; Muchowicz, L.; Mendak, D.; Kalarus, L. (2007). Verification of the mathematical model of heat transfer in the continuous casting tundish. Metallurgy - Metallurgical Engineering news, No. 7, (July 2007), pp. 350-353, ISSN 1230-3534

Rogler, J.P.; Heaslip, L.J.; Mehrvar, M. (2005). Physical modeling of inclusion removal in a tundish by gas bubbling. Canadian Metall. Quarterly, Vol. 44, No. 3, (July 2005), pp. 357-368, ISSN 1879-1395

Shih, T.-H.; Liou, W.W.; Shabbir, A.; Yang, Z.; Zhu, J. (1995). A new k-ع eddy-viscosity model for high Reynolds number turbulent flows - model development and validation. Computers Fluids, Vol. 24, No. 3, (March 1995), pp. 227-238, ISSN 00457930

Solorio-Diaz, G.; Morales, R.D.; Palafax-Ramos, J.; Garcia-Demedices, L.; Ramos-Banderas, A. (2004). Analysis of fluid flow turbulence in tundishes fed by swirling ladle shroud. ISIJ International, Vol. 44, No. 6, (June 2004), pp. 1024-1032, ISSN 0915-1559 
Zhang, F.; Taniguchi, S.; Cai, K. (2000). Fluid flow and inclusion removal in continuous casting tundish. Metal. and Mater. Trans. B, Vol. 31, No. 2, (April 2000), pp. 253-266, ISSN 1073-5615

Zhang, L.; Thomas, B.G.; Cai, K.; Zhu, L.; Cui, J. (2003). Inclusion investigation during clean steel production at Baosteel. ISSTech 2003, ISS, Warrandale, PA, (2003), pp. 141-156 


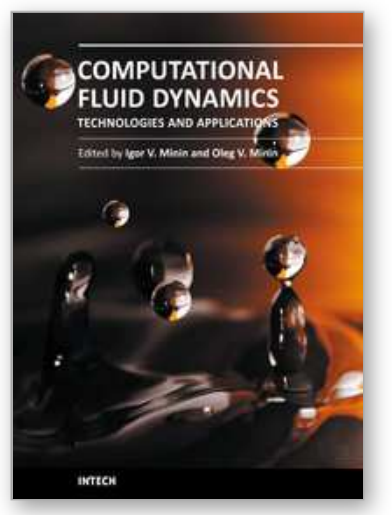

\section{Computational Fluid Dynamics Technologies and Applications}

Edited by Prof. Igor Minin

ISBN 978-953-307-169-5

Hard cover, 396 pages

Publisher InTech

Published online 05, July, 2011

Published in print edition July, 2011

This book is planned to publish with an objective to provide a state-of-art reference book in the area of computational fluid dynamics for CFD engineers, scientists, applied physicists and post-graduate students. Also the aim of the book is the continuous and timely dissemination of new and innovative CFD research and developments. This reference book is a collection of 14 chapters characterized in 4 parts: modern principles of CFD, CFD in physics, industrial and in castle. This book provides a comprehensive overview of the computational experiment technology, numerical simulation of the hydrodynamics and heat transfer processes in a two dimensional gas, application of lattice Boltzmann method in heat transfer and fluid flow, etc. Several interesting applications area are also discusses in the book like underwater vehicle propeller, the flow behavior in gas-cooled nuclear reactors, simulation odour dispersion around windbreaks and so on.

\section{How to reference}

In order to correctly reference this scholarly work, feel free to copy and paste the following:

Marek Warzecha (2011). Numerical Modelling of Non-metallic Inclusion Separation in a Continuous Casting Tundish, Computational Fluid Dynamics Technologies and Applications, Prof. Igor Minin (Ed.), ISBN: 978-953307-169-5, InTech, Available from: http://www.intechopen.com/books/computational-fluid-dynamicstechnologies-and-applications/numerical-modelling-of-non-metallic-inclusion-separation-in-a-continuouscasting-tundish

\section{INTECH}

open science | open minds

\section{InTech Europe}

University Campus STeP Ri

Slavka Krautzeka 83/A

51000 Rijeka, Croatia

Phone: +385 (51) 770447

Fax: +385 (51) 686166

www.intechopen.com

\section{InTech China}

Unit 405, Office Block, Hotel Equatorial Shanghai

No.65, Yan An Road (West), Shanghai, 200040, China

中国上海市延安西路65号上海国际贵都大饭店办公楼 405 单元

Phone: +86-21-62489820

Fax: $+86-21-62489821$ 
(C) 2011 The Author(s). Licensee IntechOpen. This chapter is distributed under the terms of the Creative Commons Attribution-NonCommercialShareAlike-3.0 License, which permits use, distribution and reproduction for non-commercial purposes, provided the original is properly cited and derivative works building on this content are distributed under the same license. 